\title{
Research Progress on Gestational Diabetes Mellitus and Endothelial Dysfunction Markers
}

This article was published in the following Dove Press journal:

Diabetes, Metabolic Syndrome and Obesity: Targets and Therapy

\author{
Yujing $\mathrm{He} \mathbb{D}^{\prime}$ \\ $\mathrm{Na} \mathrm{Wu}^{1,2}$ \\ 'Department of Endocrinology, Shengjing \\ Hospital of China Medical University, \\ Shenyang, People's Republic of China; \\ ${ }^{2}$ Department of Emergency Medicine, \\ Shengjing Hospital of China Medical \\ University, Shenyang, People's Republic of \\ China
}

\begin{abstract}
Gestational diabetes mellitus (GDM) is the onset or first recognition of diabetes during pregnancy in women with normal glucose metabolism or potentially impaired glucose tolerance before pregnancy. Studies have shown that vascular endothelial cells (VECs) are an important target organ of insulin, which is injured by multiple factors in the case of GDM, thereby leading to worsened insulin resistance (IR) and the further development of GDM. When VECs are abnormal, there will be changes in the content of a variety of cell markers, which may be helpful for the clinical prediction and diagnosis of GDM. This study attempted to investigate the mechanism and markers of VECs injury in GDM patients.
\end{abstract}

Keywords: gestational diabetes mellitus, endothelial cells, biomarkers

\section{Introduction}

Nowadays, with the gradual improvement of people's living standard, the incidence rate of GDM in the world is increasing. GDM is the abnormal glucose metabolism that does not reach the dominant diabetes level during pregnancy, which accounts for over $90 \%$ of pregnancy diabetes mellitus, and $20 \%$ to $50 \%$ of the development of type 2 diabetes mellitus (T2DM) in postpartum. The occurrence of gestational diabetes mellitus will increase the probability of complications of pregnant women, such as: abortion, polyhydramnios, macrosomia, diabetic ketoacidosis (DKA), infection, pregnancy-induced hypertension, etc., as well as shoulder dystocia, prolonged labor, postpartum hemorrhage caused by fetal overgrowth during the production process. Because of the high blood sugar environment in the mother during pregnancy, the risk of fetal malformation, macrosomia and growth restriction will also increase. ${ }^{1}$

A variety of factors trigger GDM, including inflammatory factors, adipokines, the release of anti-insulin hormones and genetic factors, etc. The classical view suggests that GDM is a consequence of the increased demand for glucose during pregnancy and relatively insufficient secretion of insulin and IR. ${ }^{1}$ In the process of GDM, vascular endothelial dysfunction is a major contributing factor which considers as the main cause of IR. Therefore, a timely understanding of the functional status of VECs is of great significance in preventing the onset, delaying the development of GDM, and lowering the potential risk of vascular complications. ${ }^{2}$

\section{Structure and Function of VECs}

VECs are a thin layer of single connected flat cells lining the interior surface of blood vessels. A normal adult has about $1 \times 10^{12} \mathrm{VECs}$, with visible round or oval apertures.
Shengiing Hospital of China, 36 Sanhao

Road, Heping District, Shenyang, Liaoning

Province, I 10004, People's Republic of

China

Tel +86 I8940258445

Email344I535223@qq.com
Diabetes, Metabolic Syndrome and Obesity: Targets and Therapy 2021:14 983-990

DovePress in $\mathbf{r}$ 
VECs secrete cytokines in an endocrine, paracrine, or autocrine way, which regulate vascular tension and blood flow and maintain the steady-state of microcirculation. ${ }^{3}$ Apart from the functions of regulating the permeability of blood vessels and maintaining the integrity of the blood vessel wall, VECs have important endocrine functions. ${ }^{4}$ They can synthesize and release a variety of endothelial-derived vasoactive factors that play an important physiological roles, such as nitric oxide (NO), endothelin-1 (ET-1), interleukin, and asymmetric dimethylarginine (ADMA). Among them, NO is the strongest relaxation factor and ET-1 is the strongest contraction factor, both of which play an important role in maintaining the vasodilation and vasoconstriction of microvessels. VECs also have anticoagulant and antithrombosis effects, thereby maintaining sufficient blood flow and flow rate in microcirculation. ${ }^{3}$ Endothelial cell dysfunction includes functional changes of the endothelium, such as impaired regulation of vasodilation and vasoconstriction, impaired or excessive angiogenesis, decreased barrier function, and increased inflammation activation.

\section{Mechanism of GDM-Induced Endothelial Cell Injury}

Among the many views, IR is the universally recognized pathophysiological basis of GDM. ${ }^{5-8}$ Researches have shown that the body of GDM patients is chronically in a low-level inflammatory response, which is not only a typical manifestation of metabolic disease, but can further promote IR injury to endothelial cells. ${ }^{9}$ It is suggested that there may be a strong association between low-level inflammatory response status and GDM and its complications. ${ }^{10-13}$ It has been reported in the literature, ${ }^{14,15}$ inflammatory factors can make the body less sensitive to insulin, but also can promote the secretion of glucocorticoids, growth hormone, and so on, so that the body appears IR, eventually leading to a persistent increase in blood glucose levels in pregnant women during pregnancy. ${ }^{16}$ Advanced glycation end products(AGEs) are the main pathological consequence of persistent hyperglycemia, which is caused by nonenzymatic glycosylation of proteins, lipids and nucleic acids. ${ }^{17,18}$ Some studies have also shown that ages and their precursors can promote oxidative stress and inflammation through binding with receptors, leading to vascular injury. ${ }^{19,20}$ It is reported that AGEs can activate some signal cascades of injured endothelial cells and play a role in the development of diabetic vascular complications. ${ }^{21}$ In addition, AGEs also cause eNOS enzyme inactivation, resulting in a decrease in NO, a higher risk of vascular endothelial cells and damage to vascular permeability. ${ }^{22-24}$

Ages mediate the activation of early growth response protein 1 (EGR-1) and its downstream factors through protein kinase C- $\beta$ II (PKC- $\beta \mathrm{II})$ and extracellular signal regulated kinase $1 / 2$ (ERK 1/2) signaling pathways (AGEs/PKC- $\beta$ II/ERK1/2/EGR-1 pathway), which trigger the secretion of proinflammatory cytokines such as interleukin-6 (IL-6), IL-1 $\alpha$, intercellular adhesion molecule-1 (ICAM-1), and tumor necrosis factor- $\alpha(\mathrm{TNF}-\alpha),{ }^{25}$ which is a new mechanism of GDM induced vascular inflammation. ${ }^{26,27}$

VECs are the most important target cells of insulin secreted in the body. In case of dysfunction, VECs will be unable to combine with insulin normally and thus fail to perform signal transduction, nor they will play the roles in regulating blood flow and directing insulin to move to their target organs and tissues, thereby worsening IR. ${ }^{28}$ The binding of insulin with special receptors on VECs can activate endothelial nitric oxide synthase (eNOS), increase NO release, and decrease ET-1 secretion, thereby leading to vasodilatation. GDM-induced high glucose, oxidative stress, and abnormal adhesion to vascular endothelium damage VECs leading to reduce NO synthesis and release. In this case, nutrient-stimulated insulin response gradually increases, and the body experiences relatively insufficient secretion of insulin. ${ }^{4}$ Pathologically high levels of insulin have multiple direct effects on VECs, affecting the synthesis and secretion of a variety of vasodilatory and vasoconstrictive factors and regulating the proliferation and apoptosis of VECs. ${ }^{29}$ In a state of lowgrade chronic inflammation, VECs undergo structural changes, which lead to the increased permeability of microvessels, the increased leakage of plasma and small molecule proteins, the decreased transport of insulin, and enhanced IR. ${ }^{30}$ The impairment of VECs functions is also the initiating factor of hypertension, which, in turn, acts on the renin-angiotensin system (RAS) of VECs, reducing NO synthesis and increasing ET-1 secretion. These responses exacerbate endothelial cell injury and progressively worsen IR. ${ }^{3}$ The relationship between these factors above is shown in Figure 1. 


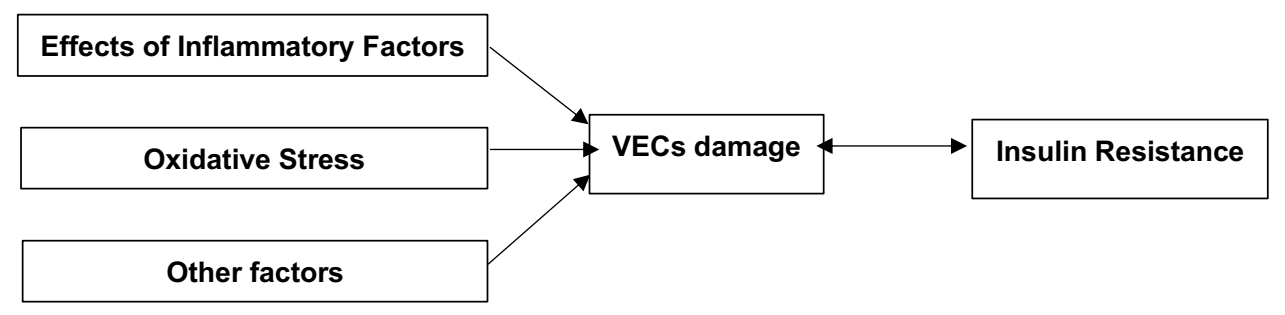

Figure I Relationship between influence factors, VECs and IR.

\section{VECs Markers}

As mentioned above, these markers are produced when VECs are damaged by high glucose and oxidative stress. Through these damaged cell markers, GDM can be indicated. At the same time, these markers can also be used to indicate the degree of endothelial cell damage, so as to predict and prevent the long-term complications of GDM.

\section{Von Willebrand Factor (vWF) and Antithrombin (AT)}

In the process of GDM, the increase of insulin release leads to the damage of VECs, so vWF and at are abnormal. ${ }^{28}$ Under normal physiological conditions, vWF is a glycosylated protein, ${ }^{3}$ which is primarily synthesized in endothelial cells and partially in megakaryocytes, playing a role in promoting platelet adhesion and aggregation, stabilizing and enhancing the function of coagulation factor VIII. ${ }^{32}$ Besides, vWF can expedite the synthesis of plasma Fib. In the event of VECs injury, vWF is abundantly released into the blood. The normal concentration of plasma vWF is about $10 \mathrm{mg} / \mathrm{L}$ but is increased when endothelial cells are stimulated or damaged or when the body is under stress. Therefore, vWF can be considered as a marker of endothelial cell injury. ${ }^{33} \mathrm{AT}$, mainly synthesized by the liver, is an important physiological anticoagulant factor in plasma, maintaining the balance between coagulation and anticoagulation. Moreover, AT also has the function of protecting blood vessels. The decrease of at activity and level will indicate the injury of vascular endothelial cells. In patients with GDM, elevated expression of vWF and reduced expression of AT in plasma suggest endothelial injury and endothelial dysfunction. Damaged endothelial cells could further promote more GDM development. Hence, the abnormal changes of $\mathrm{vWF}$ and at can be used as indicators of GDM and vascular endothelial cell injury.

\section{Tumor Necrosis Factor $\alpha$ (TNF- $\alpha$ )}

TNF- $\alpha$ is a cytokine secreted by neutrophils, monocytes, macrophages, NK cells, lymphocytes, eosinophils, and vascular endothelial cells, as well as the post-delivery placental tissue. TNF- $\alpha$ has a wide range of biological functions, such as promoting the aggregation and adhesion of inflammatory cells that cause VECs injury. TNF- $\alpha$ can directly inhibit the activity of glucose transport protein in adipocytes, reduce its expression, and enhance insulin resistance. ${ }^{16}$ According to $\mathrm{Di}$ Fulvio et $a l,{ }^{34}$ TNF- $\alpha$ stimulates VECs to increase vascular permeability and produces an inflammatory response, thereby damaging endothelial cell function. Thus, TNF- $\alpha$ acts as an inflammatory cytokine to promote the occurrence and development of GDM. Besides, their research also showed that the expression of TNF- $\alpha$ in the placental tissue of GDM patients was significantly higher than that in the normal group, and it was positively correlated with plasma TNF- $\alpha$ levels. The increased expression of TNF- $\alpha$ in placental tissue may cause damage to the placental vascular endothelium, resulting in placental dysfunction and the worsened hypoxic-ischemic state of the placenta. ${ }^{35}$ Winkler et $\mathrm{al}^{36}$ found that patients with GDM have higher serum TNF- $\alpha$ levels than normal pregnancies, and it is closely related to the degree of IR. According to Kirwan et al, ${ }^{37}$ TNF- $\alpha$ may promote the occurrence and development of GDM by damaging VECs, which suggests that the abnormal changes in TNF- $\alpha$ can be used as an indicator indicating VECs injury status. Since TNF- $\alpha$ induces the occurrence and development of GDM by mediating IR, it can be used as an indicator to predict GDM and assess its prognosis. $^{38}$

\section{Vascular Cell Adhesion Molecule-I (VCAM-I)}

VCAM-1 belongs to the immunoglobulin superfamily, which mainly plays a role in mediating the adhesion of lymphocytes, monocytes, eosinophils, and basophils to 
the vascular endothelium. It is also involved in angiogenesis, endothelial injury, and other processes, playing an important part in leukocyte-endothelial cell signal transduction. ${ }^{39}$ VCAM-1 is a biomarker of endothelial dysfunction. VCAM-1 can bind to the ligands on white blood cells (WBCs), promoting the adhesion of WBCs to VECs, which may result in VEC injury. ${ }^{40}$ Healthy pregnant women have significantly lower plasma VCAM1 levels than pregnant women with GDM. This suggests that VCAM-1 is closely associated with the onset of GDM. Researches also indicated that the placental tissue in the healthy group has significantly lower VCAM-1 expression than the GDM group and that the VCAM-1 expression in the GDM group is positively related to plasma VCAM-1 levels. Hence, it can be inferred that the high expression of VCAM1 in patients with GDM may damage placental VECs and trophoblast cells, causing placental dysfunction, fetal ischemia and hypoxia, and increasing the risk of stillbirth. ${ }^{35}$ Studies have also shown that patients with GDM experience significantly higher levels of VCAM1 than healthy pregnant women and that VCAM-1 promotes the occurrence and development of GDM by damaging VECs. Therefore, VCAM-1 levels can be detected to assess the functional status of endothelial cells, and diagnose GDM in combination with the levels of glycated hemoglobin (HbA1C) and glycated albumin (GA). ${ }^{41}$

\section{Asymmetric Dimethylarginine (ADMA)}

ADMA is an endogenous L-amino acid that widely exists in cells and tissues inside the body. ${ }^{11}$ Recent studies have shown that ADMA can be used as a clinically predictor of endothelial dysfunction. ${ }^{12}$ According to some animal studies, the action of ADMA on endothelial function is worked by affecting the endogenous nitric oxide synthase (NOS)/NO pathway. In vitro studies show that ADMA is a NOS inhibitor that induces oxidative stress by inhibiting NO synthesis, thereby causing low-grade inflammation and the resultant vascular endothelial dysfunction. ${ }^{13}$ Studies are revealing that patients with GDM have significantly higher plasma ADMA levels but significantly lower NOS and NO levels than healthy pregnant women, suggesting that patients with GDM experience abnormally elevated plasma ADMA levels. ${ }^{42}$ According to
Mittermayer et al, ${ }^{43}$ 14-16 weeks after delivery, patients with GDM experience higher plasma ADMA levels than healthy pregnant women. The injury of ADMA to VECs further promotes the occurrence and development of GDM. ${ }^{44}$ These findings indicate that ADMA levels can be used as an indicator to identify whether VECs are injured, ${ }^{45}$ and has the potential to serve as an indicator to diagnose GDM and assess the severity of the disease. ${ }^{46}$

\section{Vascular Endothelial (VE)-Cadherin}

VE-cadherin is a VEC-specific cadherin, the main adhesion molecule on VECs. ${ }^{47}$ It is located at junctions between endothelial cells and plays an important role in maintaining the integrity and physiological function of endothelial cells. Studies have shown that the expression of VE-cadherin can be used to indirectly infer whether there are increased vascular permeability and VECs injury, and thus to assess the degree of vascular endothelial dysfunction. Besides, VEcadherin is found to play a role in pathological processes such as diabetes, and gestational hypertension. Recent studies $^{48}$ have also found that serum VEcadherin levels in patients with GDM are significantly higher than that in the normal control group and that elevated levels of serum VE-cadherin increase the incidence of macrosomia and promote the occurrence of GDM. Therefore, VE-cadherin levels indirectly indicate the functional status of VECs, promising to be one of the predictors of GDM. ${ }^{48}$

\section{Soluble Intercellular Adhesion Molecule- I (sICAM-I)}

sICAM-1 is a member of the immunoglobulin superfamily. Plasma sICAM-1 contains most of the sequences within the extracellular domain of membrane-bound ICAM-1, and it binds to lymphocyte function-associated antigen 1 (LFA-1). ICAM-1 vascular expression is rare under normal physiological conditions, while pathogenic factors, such as hyperglycemia, activate its expression in endothelial cells, and an increase in sICAM-1 is also produced, reflecting VECs activation and dysfunctionality. ${ }^{49}$ In the course of GDM, hyperglycemia stimulates adenosine diphosphate (ADP)-activated platelets to induce endothelial cells to express sICAM-1, and meanwhile, it increases 
the response of platelets to ADP stimulation. In the case of hyperglycemia, AGEs increases, which may also induces increased expression of sICAM-1. ${ }^{50} \mathrm{Su}$ et $\mathrm{al}^{50}$ showed that sICAM-1 was significantly increased in patients with GDM, which results indicate that there is a dysfunction of vascular endothelial function in pregnant women with GDM. Chen Ying et $\mathrm{al}^{51}$ indicated that the serum sICAM-1 level in GDM group was significantly increased. Monitoring the serum sICAM-1 level of GDM patients is helpful to understand the abnormal state of endothelial cells in pregnant women, the degree of IR, and to evaluate the incidence of GDM. ${ }^{52}$

\section{Plasminogen Activator Inhibitor-I (PAI-I)}

PAI-1, a single-chain globular protein which coupled with tissue-type plasminogen activator, is considered to be a pair of key substances that regulates the fibrinolytic activity. Both the substances are synthesized in VECs and released into the blood after synthesis. Under physiological conditions, PAI-1 can be produced in hepatocytes, but under inflammatory conditions, it will be abundantly secreted in VECs induced by inflammatory factors. ${ }^{54}$ Considering the common characteristics of pathogenesis between GDM and T2DM, of whom PAI-1 is considered as a classic predictor, Salmi et $\mathrm{al}^{53}$ explored the correlation between GDM and PAI-1 and concluded that PAI-1 levels were abnormally elevated in patients with GDM. According to Yan et al, ${ }^{54}$ the significant elevation of plasma PAI-1 levels in patients with GDM was closely associated with IR, and therefore PAI-1 was involved in the onset of GDM. These findings suggest that PAI-1 has the potential to serve as a predictor of GDM. ${ }^{55}$

\section{Damage of Endothelial Cell Injury During GDM}

There are studies have shown that women with gestational diabetes mellitus and mild gestational impaired glucose tolerance are at increased risk for type 2 diabetes and cardiovascular disease in the future. ${ }^{56}$ A retrospective population-based cohort study in Canada examined the effect of gestational diabetes mellitus on vascular disease at 11.5 years postpartum, suggesting an association between GDM and vascular disease. ${ }^{57}$ In the investigation of Freire et al. ${ }^{58}$ compared with the control group, women with gestational diabetes mellitus had increased carotid intima-media thickness (an early alternative marker of cardiovascular disease). Alexandra Oliveira et $\mathrm{al}^{59}$ studied the changes of diastolic function in women with GDM, which is often one of the first symptoms of cardiovascular disease in the future. The results of echocardiography showed that the thickness of posterior wall and interventricular septum was higher, the left ventricular mass and left ventricular mass index increased. There was a positive correlation between left ventricular mass index and fasting blood glucose and gestational body mass index, suggesting that the heart of patients with gestational diabetes mellitus has mild dysfunction. ${ }^{59}$

Studies have shown that women with gestational diabetes mellitus and mild gestational impaired glucose tolerance have an increased risk of type 2 diabetes and cardiovascular disease in the future. ${ }^{60}$ In women, high glucose during pregnancy predicts a gradient in the future risk of cardiovascular disease, which manifests itself over the next few decades. ${ }^{61-63}$ The current view is that over the time, exposure to enhanced cardiovascular risk factor can lead to vascular injury and dysfunction, which is an early event in the process of atherosclerosis.

\section{Conclusion}

In the pathogenesis of GDM, VECs are damaged by a variety of factors, such as inflammatory factors and oxidative stress. VECs injury leads to IR and promotes the development and progression of GDM disease. At the same time, the development of GDM further damaged vascular endothelial cells.

From the above discussion, it can be revealed that indicators including vWF/AT, TNF- $\alpha$, VCAM-1, ADMA, VE-cadherin, sICAM-1, and PAI-1 reflect the functional changes of endothelial cells, so they promise to be the predictor of GDM and the revision guide of GDM risk factors. The summary of these indicators can be viewed in Table 1. These indicators are probably of new significance in clinical practice for the prevention and treatment of GDM, for example, applying TNF- $\alpha$ and VCAM-1 to the monitoring of intrauterine and fetal conditions. ${ }^{36}$ However, the changes in these indicators and their roles in the pathogenetic mechanism of GDM remain to be explored, needing more prospective researches. At the same time, in clinical work, special attention should be contributed to the abnormal changes in these indicators. 
Table I Biomarkers and Characteristics of Endothelial Cells

\begin{tabular}{|c|c|c|c|c|c|}
\hline $\begin{array}{l}\text { Author and } \\
\text { Year }\end{array}$ & Biomarkers & Synthetic Site & $\begin{array}{l}\text { Changes } \\
\text { in GDM }\end{array}$ & Effect & $\begin{array}{l}\text { Mechanism of Action in } \\
\text { GDM }\end{array}$ \\
\hline $\begin{array}{l}\text { Malyszko J, } 2008^{32} \\
\text { Zhang X, } 2009^{33}\end{array}$ & vWF & $\begin{array}{l}\text { Endothelial cells, } \\
\text { megakaryocytes, } \\
\text { etc }\end{array}$ & Rise & $\begin{array}{l}\text { Promote platelet adhesion and } \\
\text { aggregation and stabilize coagulation } \\
\text { function }\end{array}$ & Increase the degree of IR \\
\hline Wang F, $2014^{28}$ & AT & Liver & Reduce & $\begin{array}{l}\text { Maintain the balance of coagulation } \\
\text { function }\end{array}$ & Increase the degree of IR \\
\hline $\begin{array}{l}\text { Di Fulvio P, } 2014^{34} \\
\text { Winkler G2002 }\end{array}$ & TNF- $\alpha$ & $\begin{array}{l}\text { Neutrophils, } \\
\text { macrophages, etc }\end{array}$ & Rise & $\begin{array}{l}\text { Promote the aggregation and adhesion } \\
\text { of inflammatory cells }\end{array}$ & $\begin{array}{l}\text { Increased TNF - } \alpha \text { level } \\
\text { results in endothelial injury of } \\
\text { placenta }\end{array}$ \\
\hline $\mathrm{Li} \mathrm{H}, 2012^{40}$ & VCAM-I & Endothelial cells & Rise & $\begin{array}{l}\text { Mediating adhesion of leukocytes to } \\
\text { vascular endothelium }\end{array}$ & $\begin{array}{l}\text { Placental injury caused by } \\
\text { elevated VCAM-I level }\end{array}$ \\
\hline $\begin{array}{l}\text { Jin ZW, } 2018^{42} \\
\text { Mittermayer F, } \\
2002^{43}\end{array}$ & ADMA & Widespread & Rise & Inhibition of NOS/no pathway & $\begin{array}{l}\text { Induced oxidative stress, } \\
\text { leading to low levels of } \\
\text { inflammation }\end{array}$ \\
\hline Ding GC, $2016^{48}$ & VE-cadherin & Endothelial cells & Rise & $\begin{array}{l}\text { Maintain the integrity of endothelial } \\
\text { cells }\end{array}$ & $\begin{array}{l}\text { Increased incidence of } \\
\text { macrosomia }\end{array}$ \\
\hline $\begin{array}{l}\text { Su N, } 2013^{50} \\
\text { Chen Y, } 2016^{51}\end{array}$ & sICAM-I & Widespread & Rise & $\begin{array}{l}\text { Play the role of the body in regulating } \\
\text { cell adhesion }\end{array}$ & Indicate the degree of IR \\
\hline $\begin{array}{l}\text { Salmi AA, } 2012^{53} \\
\text { Yan YH, } 2010^{54}\end{array}$ & PAI-I & $\begin{array}{l}\text { Endothelial cells } \\
\text { and hepatocytes }\end{array}$ & Rise & Regulate fibrinolytic activity & Indicate the degree of IR \\
\hline
\end{tabular}

\section{Abbreviations}

GDM, gestational diabetes mellitus; VECs, vascular endothelial cells; IR, insulin resistance; T2DM, type 2 diabetes; DKA, diabetic ketoacidosis; NO, nitric oxide; ET-1, endothelin-1; ADMA, asymmetric dimethylarginine; eNOS, endothelial nitric oxide synthase; RAS, the reninangiotensin system; vWF, von Willebrand Factor; AT, antithrombin; TNF- $\alpha$, tumor necrosis factor $\alpha$; VCAM- 1 , vascular cell adhesion molecule-1; WBCs, white blood cells; HbA1C, glycated hemoglobin; GA, glycated albumin; NOS, nitric oxide synthase; VE, vascular endothelial; sICAM-1, soluble intercellular adhesion molecule-1; LFA1, lymphocyte function-associated antigen 1; AGEs, advanced glycation end products; PAI-1, plasminogen activator inhibitor-1.

\section{Statement of Ethics}

This article does not contain any studies with human or animals performed by any of the authors.

\section{Consent for Publication}

This manuscript does not apply.

\section{Author Contributions}

All authors made a significant contribution to the work reported, whether that is in the conception, analysis and interpretation; took part in drafting, revising or critically reviewing the article; gave final approval of the version to be published; have agreed on the journal to which the article has been submitted; and agree to be accountable for all aspects of the work.

\section{Funding}

This research was supported by the National Natural Science Foundation of China (grant No. 81700706), the 345 Talent Project of Shengjing Hospital and the Clinical Research Project of Liaoning Diabetes Medical Nutrition Prevention Society (grant No. LNSTNBYXYYFZXHRS01B). 


\section{Disclosure}

The authors declare no conflicts of interest in this work.

\section{References}

1. Yuan NX, Zhai H, Du DQ, Xu S, Wang M. Progress in research on the pathogenesis of gestational diabetes mellitus. $J$ Guangxi Med Univ. 2019;36(02):321-324.

2. Siddiqui K, George TP, Nawaz SS, Joy SS. VCAM-1, ICAM-1 and selectins in gestational diabetes mellitus and the risk for vascular disorders. Future Cardiol. 2019;15(5):339-346. doi:10.2217/fca2018-0042

3. Gao YH, Liu JZ, Wang RS, Zhang NP. Research progress on the relationship between vascular endothelial cell function and diabetes mellitus. J Shanxi Datong Univ. 2020;36(04):50-54.

4. Sun CL. The structure and function of vascular endothelial cells. Biol Bull. 1991;180(09):12-13. doi:10.2307/1542425

5. Rotter V, Nagaev I, Smith U. Interleukin-6 (IL-6) induces insulin resistance in 3T3-L1 adipocytes and is, like IL-8 and tumor necrosis factor-alpha, overexpressed in human fat cells from insulin-resistant subjects. J Biol Chem. 2003;278(46):45777-45784. doi:10.1074/jbc. M301977200

6. Sayin R, Aslan M, Kucukoglu ME, et al. Serum prolidase enzyme activity and oxidative stress levels in patients with diabetic neuropathy. Endocrine. 2014;47(1):146-151. doi:10.1007/s12020013-0136-3

7. Lappas M, Hiden U, Desoye G, Froehlich J, Hauguel-de MS, Jawerbaum A. The role of oxidative stress in the pathophysiology of gestational diabetes mellitus. Antioxid Redox Signal. 2011;15 (12):3061-3100. doi:10.1089/ars.2010.3765

8. Yuan J. Study on the Role of Inflammatory Pathways of LPS-TLR4$N F-K b$ in Pathogenesis of GDM. Anhui Medical University; 2016.

9. Peng HY, Li HP. Regulation of miR-137 overexpressed trophoblast cells on biological functions of vascular endothelial cells. $J$ Shanghai Jiaotong Univ. 2017;37(10):1350-1356.

10. Ozgu-Erdinc AS, Yilmaz S, Yeral MI, Seckin KD, Erkaya S, Danisman AN. Prediction of gestational diabetes mellitus in the first trimester: comparison of C-reactive protein, fasting plasma glucose, insulin and insulin sensitivity indices. J Matern Fetal Neonatal Med. 2015;28(16):1957-1962. doi:10.3109/14767058.2014.973397

11. Wojcik M, Zieleniak A, Zurawska-Klis M, Cypryk K, Wozniak LA. Increased expression of immune-related genes in leukocytes of patients with diagnosed gestational diabetes mellitus (GDM). Exp Biol Med (Maywood). 2016;241(5):457-465. doi:10.1177/1535370215615699

12. Moreli JB, Correa-Silva S, Damasceno DC, et al. Changes in the TNF-alpha/IL-10 ratio in hyperglycemia-associated pregnancies. Diabetes Res Clin Pract. 2015;107(3):362-369. doi:10.1016/j. diabres.2015.01.005

13. Syngelaki A, Kotecha R, Pastides A, Wright A, Nicolaides KH. Firsttrimester biochemical markers of placentation in screening for gestational diabetes mellitus. Metabolism. 2015;64(11):1485-1489. doi:10.1016/j.metabol.2015.07.015

14. Dongel I, Gokmen AA, Gonen I, Kaya S. Pentraxin-3 and inflammatory biomarkers related to posterolateral thoracotomy in thoracic surgery. Pak J Med Sci. 2019;35(2):464-469. doi:10.12669/pjms.35.2.181

15. Liu QH. Correlation between gestational management and pregnancy outcome in pregnant women with gestational diabetes mellitus. Matern Child Health Care Chin. 2016;31(02):271-273.

16. Li HB, Ling M, Zhou SR. Relationship between inflammatory factors and insulin resistance in patients with gestational diabetes mellitus. Chin Community Doctors. 2020;36(33):126-127.

17. Booth AA, Khalifah RG, Todd P, Hudson BG. In vitro kinetic studies of formation of antigenic advanced glycation end products (AGEs). Novel inhibition of post-Amadori glycation pathways. $J$ Biol Chem. 1997;272(9):5430-5437. doi:10.1074/jbc.272.9.5430
18. Forbes JM, Thallas V, Thomas MC, et al. The breakdown of preexisting advanced glycation end products is associated with reduced renal fibrosis in experimental diabetes. FASEB J. 2003;17 (12):1762-1764. doi:10.1096/fj.02-1102fje

19. Wendt T, Bucciarelli L, Qu W, et al. Receptor for advanced glycation endproducts (RAGE) and vascular inflammation: insights into the pathogenesis of macrovascular complications in diabetes. Curr Atheroscler Rep. 2002;4(3):228-237. doi:10.1007/s11883-002-0024-4

20. Loughlin DT, Artlett CM, Kango-Singh M. Precursor of advanced glycation end products mediates ER-stress-induced caspase-3 activation of human dermal fibroblasts through $\mathrm{NAD}(\mathrm{P}) \mathrm{H}$ oxidase 4. PLoS One. 2010;5(6):e11093. doi:10.1371/journal.pone.0011093

21. Yamagishi S, Nakamura N, Suematsu M, Kaseda K, Matsui T. Advanced glycation end products: a molecular target for vascular complications in diabetes. Mol Med. 2015;21(Suppl 1):S32-S40. doi:10.2119/molmed.2015.00067

22. Ueda S, Yamagishi S, Yokoro M, Okuda S. Role of asymmetric dimethylarginine in cardiorenal syndrome. Curr Pharm Des. 2014;20(14):2448-2455. doi:10.2174/13816128113199990480

23. Ojima A, Ishibashi Y, Matsui T, et al. Glucagon-like peptide-1 receptor agonist inhibits asymmetric dimethylarginine generation in the kidney of streptozotocin-induced diabetic rats by blocking advanced glycation end product-induced protein arginine methyltranferase-1 expression. Am J Pathol. 2013;182(1):132-141. doi:10.1016/j.ajpath.2012.09.016

24. Ando R, Ueda S, Yamagishi $S$, et al. Involvement of advanced glycation end product-induced asymmetric dimethylarginine generation in endothelial dysfunction. Diab Vasc Dis Res. 2013;10 (5):436-441. doi:10.1177/1479164113486662

25. Krishnasamy S, Rajaraman B, Ravi V, et al. Association of advanced glycation end products (AGEs) with endothelial dysfunction, oxidative stress in gestational diabetes mellitus (GDM). Int J Diabetes Dev C. 2020;40(2):276-282. doi:10.1007/s13410-019-00766-7

26. Rajaraman B, Ramadas N, Krishnasamy S, et al. Hyperglycaemia cause vascular inflammation through advanced glycation end products/early growth response-1 axis in gestational diabetes mellitus. Mol Cell Biochem. 2019;456(1-2):179-190. doi:10.1007/s11010019-03503-0

27. Sisay M, Edessa D, Ali T, Mekuria AN, Gebrie A, Spradley FT. The relationship between advanced glycation end products and gestational diabetes: a systematic review and meta-analysis. PLoS One. 2020;15 (10):e240382. doi:10.1371/journal.pone.0240382

28. Wang F, Liu YP, Xiao KZ, Wang ZC. The role of selective insulin resistance in vascular endothelial dysfunction. Prog Physiol Sci. 2014;45(01):64-67.

29. Ding L, Zhang J. Effects of insulin on endothelial cells. Int J Endocrinol Metab. 2010;(05):337-339.

30. Peng DZ. Clinical significance of antithrombin $ш$ and D-dimer testing in patients of gestational diabetes mellitus. Chin Med Herald. 2012;9(10):109-110.

31. Maimaitikulban T, Abratti P, Abdura Z. Association between prethrombotic state and CYP2C19, ALDH2 gene polymorphisms in type 2 diabetes mellitus patients with coronary heart disease and hypertension. Occup Health. 2016;32(10):1379-1383.

32. Malyszko J, Tymcio J. Thrombin activatable fibrinolysis inhibitor and other hemostatic parameters in patients with essential arterial hypertension. Pol Arch Med Wewn. 2008;118(1-2):36-41.

33. Zhang X, Halvorsen K, Zhang CZ, Wong WP, Springer TA. Mechanoenzymatic cleavage of the ultralarge vascular protein von Willebrand factor. Science. 2009;324(5932):1330-1334. doi:10.1126/ science. 1170905

34. Di Fulvio P, Pandolfi A, Formoso G, et al. Features of endothelial dysfunction in umbilical cord vessels of women with gestational diabetes. Nutr Metab Cardiovasc Dis. 2014;24(12):1337-1345. doi:10.1016/j.numecd.2014.06.005 
35. Zhao LL, Yang XQ. Expression and correlation of TNF- $\alpha$ and VCAM-1 in gestational diabetes mellitus. J Med Res. 2019;48 (04):78-82.

36. Winkler G, Cseh K, Baranyi E, et al. Tumor necrosis factor system in insulin resistance in gestational diabetes. Diabetes Res Clin Pract. 2002;56(2):93-99. doi:10.1016/S0168-8227(01)00355-2

37. Kirwan JP, Hauguel-de MS, Lepercq J, et al. TNF-alpha is a predictor of insulin resistance in human pregnancy. Diabetes. 2002;51 (7):2207-2213. doi:10.2337/diabetes.51.7.2207

38. Coughlan MT, Oliva K, Georgiou HM, Permezel JM, Rice GE. Glucoseinduced release of tumour necrosis factor-alpha from human placental and adipose tissues in gestational diabetes mellitus. Diabet Med. 2001;18 (11):921-927. doi:10.1046/j.1464-5491.2001.00614.x

39. Yang R, Gulixiaxi MHYTJ. Relationship between levels of APN, VCAM-1 in umbilical cord blood and macrosomia born by women with gestational diabetes mellitus. Chin Med Herald. 2016;13(24):109-112.

40. Li H, Peng W, Jian W, et al. ROCK inhibitor fasudil attenuated high glucose-induced MCP-1 and VCAM-1 expression and monocyte-endothelial cell adhesion. Cardiovasc Diabetol. 2012;11 (1):65. doi:10.1186/1475-2840-11-65

41. Zhu TS, Huang DP. Diagnostic value of combined detection of $\mathrm{HbA1c}$, GA and vascular endothelial injury biomarkers for gestational diabetes mellitus. Clin Med Eng. 2017;24(04):527-528.

42. Jin ZW, Huang HM. Changes in plasma asymmetric dimethylarginine level in patients with gestational diabetes mellitus and its correlation with plasma NO and NOS levels. Shandong Med J. 2018;58(03):56-58.

43. Mittermayer F, Mayer BX, Meyer A, et al. Circulating concentrations of asymmetrical dimethyl-L-arginine are increased in women with previous gestational diabetes. Diabetologia. 2002;45(10):1372-1378. doi:10.1007/s00125-002-0916-4

44. Wang L, Zhang SY. A new marker of vascular endothelial injury asymmetric dimethylarginine. Chin J Clin. 2011;5(16):4795-4798.

45. Feliers D, Lee DY, Gorin Y, Kasinath BS. Symmetric dimethylarginine alters endothelial nitric oxide activity in glomerular endothelial cells. Cell Signal. 2015;27(1):1-5. doi:10.1016/j.cellsig.2014.09.024

46. Meng R, Xu JS, Xu J. Study on the relationship between asymmetric dimethylarginine and vascular endothelial dysfunction in gestational diabetes mellitus patients. China Modern Doctor. 2017;55(18):161-164.

47. Li B, Wang X, Shang LX. Observation on the efficacy of individualized medical nutrition therapy combined with exercise therapy on gestational diabetes mellitus. Shandong Med J. 2014;54(36):87-89.

48. Ding GC, Zhang QX, Chen WG, Gu CM. Detection and clinical significance of VE-cadherin in intravenous serum of gestational diabetes mellitus. Diabetes New World. 2016;19(06):80-81.

49. Echeverria C, Eltit F, Santibanez JF, Gatica S, Cabello-Verrugio C, Simon F. Endothelial dysfunction in pregnancy metabolic disorders. Biochim Biophys Acta. 2020;1866(2):165414. doi:10.1016/j. bbadis.2019.02.009

50. Su N, Fu DX, Wang GY, Xu JX, Xing BH, Wang RY. Relationship between hs-CRP sICAM-1 and insulin resistance in patients with gestational diabetes. Shanxi Med J. 2013;42(04):372-374.
51. Chen Y. Changes of lipopolysaccharide, nuclear factor- $\mathrm{kB}$, soluble intercellular adhesion molecule-1, and adiponectin levels in patients with gestational diabetes and their significance. Chin J Clin. 2016;44 (05):88-90.

52. Cho SH, Ryu CH, Oh CK. Plasminogen activator inhibitor-1 in the pathogenesis of asthma. Exp Biol Med (Maywood). 2004;229 (2):138-146. doi:10.1177/153537020422900202

53. Salmi AA, Zaki NM, Zakaria R, Nor AA, Rasool AH. Arterial stiffness, inflammatory and pro-atherogenic markers in gestational diabetes mellitus. Vasa. 2012;41(2):96-104. doi:10.1024/0301-1526/ a000171

54. Yan YH, Lu JQ, Feng ZJ, Song BB, Xu K. Investigation on correlation between PAI-1 and insulin resistance in patients with gestational diabetes mellitus. Matern Child Health Care Chin. 2010;25 (25):3541-3543

55. Cui MX, Yan M. Research progress in inflammatory factors of early prediction for gestational diabetes mellitus. J Reprod Med. 2016;25 (06):571-574.

56. Nerenberg K, Daskalopoulou SS, Dasgupta K. Gestational diabetes and hypertensive disorders of pregnancy as vascular risk signals: an overview and grading of the evidence. Can J Cardiol. 2014;30 (7):765-773. doi:10.1016/j.cjca.2013.12.030

57. Shah BR, Retnakaran R, Booth GL. Increased risk of cardiovascular disease in young women following gestational diabetes mellitus. Diabetes Care. 2008;31(8):1668-1669. doi:10.2337/dc08-0706

58. Freire CM, Barbosa FB, de Almeida MC, et al. Previous gestational diabetes is independently associated with increased carotid intimamedia thickness, similarly to metabolic syndrome - a case control study. Cardiovasc Diabetol. 2012;11:59. doi:10.1186/1475-284011-59

59. Oliveira AP, Calderon IM, Costa RA, Roscani MG, Magalhaes CG, Borges VT. Assessment of structural cardiac abnormalities and diastolic function in women with gestational diabetes mellitus. Diab Vasc Dis Res. 2015;15(3):175-180. doi:10.1177/1479164114563302

60. Bajaj HS, Ye C, Hanley AJ, Sermer M, Zinman B, Retnakaran R. Biomarkers of vascular injury and endothelial dysfunction after recent glucose intolerance in pregnancy. Diab Vasc Dis Res. 2018;15(5):449-457. doi:10.1177/1479164118779924

61. Retnakaran R. Glucose tolerance status in pregnancy: a window to the future risk of diabetes and cardiovascular disease in young women. Curr Diabetes Rev. 2009;5(4):239-244. doi:10.2174/ 157339909789804378

62. Retnakaran R, Shah BR. Mild glucose intolerance in pregnancy and risk of cardiovascular disease: a population-based cohort study. CMAJ. 2009;181(6-7):371-376. doi:10.1503/cmaj.090569

63. Retnakaran R, Shah BR. Role of type 2 diabetes in determining retinal, renal, and cardiovascular outcomes in women with previous gestational diabetes mellitus. Diabetes Care. 2017;40(1):101-108. doi:10.2337/dc16-1400

Diabetes, Metabolic Syndrome and Obesity: Targets and Therapy

\section{Publish your work in this journal}

Diabetes, Metabolic Syndrome and Obesity: Targets and Therapy is an international, peer-reviewed open-access journal committed to the rapid publication of the latest laboratory and clinical findings in the fields of diabetes, metabolic syndrome and obesity research. Original research, review, case reports, hypothesis formation, expert opinion and commentaries are all considered for publication. The manuscript management system is completely online and includes a very quick and fair peer-review system, which is all easy to use. Visit http://www.dovepress.com/testimonials.php to read real quotes from published authors. 